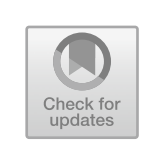

\title{
Tinkering with/in the Multicultural Science Education Debate: Towards Positing $A n$ (Other) Ontology
}

The purpose of this chapter ${ }^{1}$ is to continue working within and against the stratified and sedimented spaces of the multicultural science education debate by sustaining the deconstructive play of (re)signification of science education, labouring between what it is, is not, and could be(come). This extends upon the previous chapters' work of (re)opening this debate by engaging in the play of (re)signification between the two predominant positions (i.e., cross-culturalist and universalist) as well as the modes through which the debate operates (e.g., dialectic, debate, critique as mirroring). Putting to work the alternative optical metaphors of the previous chapter (i.e., prism and diffraction grating), I consider how these common occurrences which present themselves with/in the multicultural science education debate are co-constituted by the uncommon and usually absent (see Derrida, 1976). This, in turn, allows for an exploration of the absent yet present ${ }^{2}$ co-constitutive elements of the multicultural science education debate that produces the ways in which Indigenous science is to-come, deferring and differing its arrival.

Particularly, this chapter engages the ontological homework of response-ability: addressing the ways in which ontology, as absent presence, is always already (re)shaping science education. As signalled in Chapter 3, Cobern and Loving (2008) remind that attention to ontology is uncommon within the multicultural science education debate. Where Cobern and Loving (2008) conclude that knowing nature through WMS

(C) The Author(s) 2021

M. Higgins, Unsettling Responsibility in Science Education, Palgrave Studies in Educational Futures, https://doi.org/10.1007/978-3-030-61299-3_5 
is universal and "common sense", I latch onto the binary co-constitution of common and uncommon, and moments in which they vacillate, as a lever to (re)open spaces of science education to other meanings (e.g., Indigenous science to-come). Drawing from an ethic of deconstructive tinkering (Derrida, 1976) by using concepts, categories, and constructs that are uncommon to the context of science education to explore that which is common, ${ }^{3}$ I tinker with/in Cobern and Loving's (2008) criteria of ontological alignment to unsettle and (re)situate their claim of "common sense" towards (re)opening the logics of the multicultural science education debate.

As tinkering is central to this arc, (i.e., Chapters 5 and 6), I begin this chapter by quickly touching on what it means to engage with this process before moving to the task of tinkering with/in the multicultural science education debate.

\section{A Preamble on Tinkering: Derrida on the Porous Dichotomy Between Bricolage AND ENGineering}

To frame the process of tinkering within this section, I turn to Derrida's (1976) (mis)reading of Lévi-Strauss' La pensée sauvage in which he both separates and blurs the distinctiveness between engineering and bricolage. In short, both engineering and bricolage are processes of and for generating knowledge claims. Engineering is the movement from the ends to the means, whereby the engineer makes appropriate selections from "the discourses of formal logic, and the pure sciences" (Spivak, 1976, p. xix), picking concepts, categories, and constructs already purposed for their process. In contrast, "the bricoleur makes do with things that were meant perhaps for other ends" (Spivak, 1976, p. xix). Through tinkering, bricolage reverses the ends/means hierarchy by privileging the means over the ends or the process over the product, even if this entails the very possibility of not achieving the specified goals. ${ }^{4}$ Significantly, as Derrida (1976) argues, the ends (i.e., knowledge, truth) and the means of knowledge production (i.e., methodology) never come to coincide. The goal of (fully) achieving knowledge is not only empirically impossible, as LéviStrauss posited, but also theoretically so. Thus, for Derrida (1976), "the engineer should always be a sort of bricoleur" (p. 139) while coming to recognize the very limitation of bricolage: 
The only weakness of bricolage - but, seen as a weakness is it not irremediable? - is a total inability to justify itself in its own discourse. The already-there-ness of instruments and of concepts cannot be undone or re-invented. (pp. 138-139)

Just as the goals of engineering never come to be, Derrida cautions against treating the bricoleur's tools as if they themselves always were (i.e., having reached the classical ontological status of Being). Instead, he invites consideration of the tools themselves as the productive enactments of bricolages past and to-come (see also Barad, 2010). There is always a need for "simultaneously troubling and using the concepts [and conceptual lines] we think we cannot think without..., keeping [them] as both limit and resource" (Lather, 2007, pp. 167-168). Furthermore, because engineering/bricolage is always already a porous binary, this invites a critical consideration of bricolage vis-à-vis its ends, or what it produces: "all bricolages are not equally worthwhile. Bricolage criticizes itself" (Derrida, 1976, p. 139).

\section{Having and Being Had by "Common Sense" During a Science Education Project in Nunavut}

Because we must "begin" some-where and some-time, let's "begin" (once again $)^{5}$ in Iqualuit, Nunavut in July of $2009 .{ }^{6}$ During the delivery of a curriculum in the Canadian arctic in which Indigenous (i.e., Inuit) and non-Indigenous youth explored differential cultural constructions of science through videography (see Higgins, 2011, 2014), I took up the call to examine and challenge the ways in which Eurocentrism "insidiously ... maintain[s] the status quo" (Sammel, 2009, p. 65l; see also Belczewski, 2009; McKinley, 2001, 2007) through involving youth in revealing, (re)structuring, and (re)directing the multiple ways in which dominance is maintained. I worked towards disrupting the concepts and categories that tend to create, and are utilized to uphold, inequality within science education, as well as the systems under which these inequalities become possible. Through this project, the youth involved learned and enhanced their movie-making skills and practices in order to explore, define, and document the diverse ways-of-knowing-Nature (i.e., science) that were enacted in their community of Iqaluit, Nunavut. This participant-directed videography work took various shapes: documentarystyle interviews with community members within science and technology 
fields, as well as their own short movies which were a form of digital storytelling. Given that such an examination must also include the many bodies that occupy and uphold these systems within science education, I decided to engage simultaneously with the oft-cited "solution" of self-reflexivity through video diaries to analyse my/self as decolonizing pedagogue. Guiding this examination were questions into the ways in which I was participating in, (re)producing, and (re)produced by the culture of power.

This was useful in creating partial and side-long glances rather than penetrating gazes, producing complex and contradictory accounts of self. I was able to reveal/learn from some of the ways in which I was produced by and producing the culture of power within science education, and inadvertently pivoting rather than "transforming" my pedagogies and self as pedagogue. Nonetheless, through revisiting this data, it became apparent that I was reifying Eurocentrism through the very process of working against it. But then, as Battiste (2005) states, we cannot treat Eurocentrism as a mere individually held prejudice that we can easily cast aside with enough knowledge as its pervasiveness renders it common sensical. As briefly mentioned in previous chapters, within this major research endeavour the decolonizing curriculum (e.g., border crossing) and "teacher-as-researcher" identities (e.g., culture broker) available worked both within and against a problematic centre. As such, curriculum, pedagogy, and pedagogue were exceeded in pedagogical practice by the very coloniality the approach worked against, thus becoming de/colonizing (Higgins, 2014; see also Carter, 2004, 2010). One could say that the common pervaded the uncommon; I held but was also being held by "common sense".

As stated earlier, the very concepts we hold are always already exceeded by lived experience; lived experience provides deconstructive openings to think and act otherwise (Bohm, 1996; Wildcat, 2005). More than a niggling doubt about the porosity of that which earlier seemed solid, this double(d) pattern of holding and being held by "common sense" would become a location in which I would come to tinker. On being held by "common sense," Battiste (2005) reminds that Eurocentrism is a "consciousness in which all of us have been marinated" (p. 124, emphasis mine). This similarity is pronounced by difference in intensity, degree, and duration such that it comes to produce us as de/colonizing subjects differently. If how we think is part of the problem, as Lather (2007) quizzically questions us, how do we, and can we, think about how we think without using the thing with which we think? It is a project 
framed by at once by necessity and im/possibility: an impossibility that when creatively strived towards reconfigures what critical possibilities are possible (see Barad, 2007, 2010; Spivak, 1993/2009).

In attempting to think about how I think, one of the most significant observations that I made through this analysis was that the continued appearance of Cartesianism as a common thread. At the time, I understood Cartesianism as "both the belief that various meanings and materialities are discrete quantities (e.g., mind/body) as well as the process through which they are separated from that which co-constitutes them" (Higgins, 2014, p. 164, emphasis added). Like others (e.g., Pillow, 2003), I saw Cartesianism as a belief relegated to the realm of epistemology (i.e., knowledge about ontology, rather than or in addition to an enactment of ontology).

However, these qualities come to describe ways-of-being (i.e., ontology) instead of, or in addition to, ways-of-knowing (i.e., epistemology). Thus, what might it mean to take insights from the previous chapter (e.g., epistemology and ontology as co-constitutive and not pre-existing practice) and come to see Cartesianism not (only) as an epistemological facet of science education but (also) as one that is ontological? While questions of epistemology often take primacy due to uneven inter-cultural interfaces (i.e., dialectic rather than dialogue), it is often productive to tinker with/in windy, indirect, and side-long approaches when the most direct path seems over-travelled without yielding the desired outcomes. Responding to Lather's (2007) question, it might be one approach to thinking without using the very thing with which you think (when the thing with which you think is part of the problem), recognizing that such is never (fully) achieved. Thus, what might it mean to (re)consider the multicultural science education debate with ontology in mind?

\section{Tinkering With/in “Common Sense," Ontology and the Multicultural Science Education Debate}

Science and justice, matter and meaning are not separate elements that intersect now and again. They are inextricably fused together, and no event, no matter how energetic, can tear them asunder. (Barad, 2010, p. 242) 
If we take seriously that "science and justice... are inextricably fused together" (Barad, 2010, p. 242), the ferocity with which the multicultural science education debate rattles taken-for-granted assumptions can be, to some, surprising (see van Eijck \& Roth, 2007). At the epicentre of this debate are questions of "what counts" as science within schoolbased curriculum. Largely at stake is the inclusion or exclusion of TEK and IWLN alongside WMS, as well as the norms through which they are included, excluded, and juxtaposed. This unresolved and unresolvable debate often presents science educators with diverse and difficult queries regarding what it means to respect students and the diverse waysof-knowing-nature that they bring with them: can science (i.e., knowing nature) and justice (i.e., respecting diverse cultural knowledges) co-exist within the science education classroom?

Between science educators who champion the inclusion of TEK and IWLN as equally valid ${ }^{7}$ ways of knowing nature (i.e., cross-culturalists; for example, Snively \& Corsiglia, 2001; Stanley \& Brickhouse, 2001) and those who do not consider these ways-of-knowing-nature as equally valid to the "universal" standard of WMS (i.e., universalists; for example, Cobern \& Loving, 2001; Siegel, 2001), this aforementioned question (and false dichotomy; see Chapters 3 and 4) continues to produce friction that is not always generative. As there continues to be an ongoing and ever-present need to respond to the conflicting and potentially incommensurable demands between epistemological validity and ethical responsiveness in science education, there have been multiple attempts to resolve the debate (see Chapter 3 ), by working towards producing modest intermediary positions that attempt to develop and enhance potential points of agreement between positions (Alsop \& Fawcett, 2010; Cobern \& Loving, 2008; van Eijck \& Roth, 2007). An example of such a point of agreement is that while universalists and cross-culturalists generally do not agree whether or not science education is or is not a frequent site of scientism, indoctrination, or imposition, they both agree that it should not be. In the last few years, attempts to labour from shared assumptions towards intermediary positions have included: (a) positing an ethics of incommensurability or co-existence (e.g. El-Hani \& de Ferreira Bandeira, 2008; El-Hani \& Mortimer, 2007; van Eijck \& Roth, 2007), (b) considering diverse and competing scientific knowledges as (re-)contextualized processes rather than inert knowledges (van Eijck \& Roth, 2007), and (c) pedagogically enacting an ethics framed by the vulnerability of not knowing (Alsop \& Fawcett, 2010). 
However, in this section, I take up the possible pathway put forth by Cobern and Loving (2008). In short, Cobern and Loving (2008) posit that most proposed and partial responses to the multicultural science education debate largely centre upon questions of epistemology. Given the predominantly socio-cultural characteristics of the debate, this is not without cause. However, Cobern and Loving come at the debate sideways by tinkering with that which remains uncommon to questions of and in science education: ontology. In response to epistemic primacy, to explore how scientific knowledges might have "characteristics of verisimilitude, vis-à-vis the real world" (p. 440), Cobern and Loving suggest that the "real world" too must be seriously considered in the equation. Thus, instead, or in addition to strictly epistemological undertakings, Cobern and Loving (2008) propose that this debate be addressed through a (re)consideration of how the subject of scientific knowledge aligns with its object, or how epistemology (i.e., Culture) aligns with ontology (i.e., Nature). Through an exploration of ontological situatedness, and within the context of the multicultural science debate, the conclusion that Cobern and Loving (2008) reach is that "epistemological realism [i.e., epistemology of WMS] is literally the common ground-the common sense-we all share" (p. 443).

Drawing from insights from the previous chapters, the purpose of this chapter is not to deny the claim made by Cobern and Loving (2008) that "Epistemological Realism Really is Common Sense" (p. 425) by presenting it through a metaphorical mirror as either fact or fairy (see Latour, 2004a). Rather, it is to tinker with this uncommon approach to justify common sense; there are productive insights to be gained through using and troubling the notion that they put forth. In particular, drawing from the Chapter 4's optical metaphors, what would it mean to treat the statement as more than true or a false reflection of reality? What insights could be gained by (re)situating a "mirroring" statement (i.e., "characteristics of verisimilitude, vis-à-vis the real world" [Cobern \& Loving, 2008, p. 440]) by thinking prismatically and diffractively with and about it? In particular, what would it mean to focus on how epistemological realism as "common sense" inflects and is inflected, how it is produced and what it produces? If epistemological realism is "common sense", to whom is it common (e.g., is the "we" in the "common sense - we all share" [Cobern \& Loving, 2008, p. 440] in fact all of us or but a particular group)? For epistemic realism to be "common sense", what epistemological and ontological criteria need to be in place? How did this "common sense" come 
to be (made) common (i.e., through dialectic rather than dialogue)? 8 What does this "common sense" produce? Is "common sense" something we have, are had by, or a combination of both? Lastly, as "science and justice, matter and meaning are not separate elements that intersect now and again" (Barad, 2010, p. 242), ${ }^{9}$ what does it mean to consider ethics and justice as co-constitutive elements of ontologically situated scientific epistemologies?

\section{EPISTEMIC REALISM AND/AS “COMMON Sense?" Ontological Situatedness AND/IN THE Multicultural Science Education Debate}

Cobern and Loving (2008) state in "Epistemic Realism is Common Sense" (p. 425) that a collusion of forces have made it such that there seems to be less discussion within science education with respect to how epistemological frameworks align with the ontological reality that they attempt to represent. These factors include, but are not limited to: the move towards constructionism and socio-constructionism in science education as well as education writ large, a growing doubt towards WMS following a series of public opinion altering watershed moments (e.g., Agent Orange, napalm, Hiroshima), as well as a Kuhn's introduction of paradigms and the sudden appearance of a plenary of competing paradigms due to an increasingly multicultural social reality. The argument made is that the move to make space for what Cobern and Loving (2008) refer to "ideas that heretofore would have been called ethnoscience and folklore, pseudoscience, and even quackery" (p. 435) has meant that the focus of science education has shifted towards epistemological pluralism as a means of attempting to account for these diversely positioned ways-of-knowing-nature. While Cobern and Loving (2008) might bemoan the impact that these diverse educational and social shifts have had, and how they have reshaped science education as it is today, others have seen these as deeply productive locations and levers to pry open the spaces of science and science education (e.g., Haraway, 1997; Latour, 1993; Snively \& Corsiglia, 2001). While I stand with the latter and disagree with the premise that Cobern and Loving (2008) put forth, there is nonetheless some merit in exploring their argument: not necessarily to prove it right or wrong, but rather to explore how it is produced, 
producible, and what it produces with/in discursive spaces of science education.

Cobern and Loving $(2001,2008)$ argue that questions of crosscultural integration, interfacing, and understanding often neglect asking questions about how these meanings necessarily interface with the nature of Nature. They state, given the plurality of epistemic frameworks, that there needs to be pragmatic criteria through which systems of knowing nature (i.e., science) are deemed valid and valuable:

Interpretations of experience are all one can know... One accepts the validity of interpretations in so far as they are pragmatically viable... Historically we [Western modern scientists and science educators] have believed in the ontological reality of the world and trust our epistemological efforts to describe that reality and yet always do our epistemologies fail to demonstrate that what we think we know really is what is. (Cobern \& Loving, 2008 , p. 433 , emphasis in original)

For Cobern and Loving (2001, 2008), among many other science educators, that criterion is experience: a statement that both universalists (e.g., Matthews, 1994; Siegel, 1997, 2001) and cross-culturalists (e.g., Aikenhead \& Michell, 2011; Barnhardt \& Kawagley, 2005, 2008; Cajete, 1999; Snively \& Corsiglia, 2001) would agree with. However, there is a significant point of deviation in how experience is both understood and enacted (e.g., experience as Truth, experience as situated and partial, having and being had by experience, ${ }^{10}$ experience as relationality). Whether intentional or unintentional, Cobern and Loving (2008) utilize this conceptual plurality and undecidability as location to present a false dichotomy:

It is true that we cannot know with certainty that perceptual and experiential experiences are significantly grounded in ontological reality. However, it is equally true that we cannot know for certain that perceptual and experiential experiences are not significantly grounded in ontological reality. (p. 441)

The false dichotomy presented here is either one in which epistemology is ontologically situated within "ontological reality" by utilizing an "ontological realism that very few educators would reject" (Cobern \& Loving, 2008, p. 437, emphasis in original) or the meaning made is anti-ontological and not grounded in reality in as meaningful a way or at all. This (false) dichotomy relies upon the absent yet present a common 
sense assumption that "ontological reality" precedes meaning making, is singular, unified, and is the ontological reality defined and enacted by WMS (see Chapter 3). Thus, by (re)presenting and casting approaches that don't fall into the classical cannon of epistemic realism into (absolute) relativism, a "a pejorative as far as [they] are concerned" (p. 437), the alternative they present is but a strawman or a trick of smoke and mirrors as discussed within the previous chapter.

Further, it can be argued that the approach presented by Cobern and Loving (2008) does not bring us closer to resolving the multicultural science education debate: it simply displaces the terms of the debate elsewhere (i.e., ontology rather than epistemology). Such a displacement (re)produces a similar but different argument whose goal is to dialectically negate, subsume, or suture over the opposing view rather than create something else, something in-between through dialogue. In other words, the ontological situatedness that Cobern and Loving (2008) call for is but another means of reaffirming science, or WMS to be specific, as universal.

However, considering the notion of ontological situatedness can still bear fruit in the context of science education: what if epistemic realism best aligned with an ontology rather than simply "ontology"?

\title{
From Ontological Alignment to Positing an Ontology in Science Education
}

\begin{abstract}
How reality is understood matters. There are risks entailed in putting forward an ontology: making metaphysical assumptions explicit exposes the exclusions on which any given conception of reality is based. But the political potential of deconstructive analysis lies not in simply recognizing the inevitability of exclusions but in insisting on accountability for the particular exclusions that are enacted and in taking the responsibility to perpetually contest and rework the boundaries. (Barad, 2007, p. 205, emphasis in original)
\end{abstract}

Cobern and Loving (2008) highlight that "we face a metaphysical choice" (p. 441) in science education: a choice bearing significance if "how reality is understood matters" (Barad, 2007, p. 205, emphasis in original). This choice is situated within the realm of metaphysics as it asks us to consider the relationship between epistemology (i.e., Culture) and ontology (i.e., Nature). Within science and science education, this relationship between 
epistemology and ontology has been understood through competing claims of weak and strong forms of relativism and realism. In other words, the way in which this has primarily been taken up by science and science education scholars is through the critical and metaphysical questioning of the extent to which epistemology aligns with ontology.

Within the context of science, as Latour (1993) posits, most scientists reject absolute relativism (i.e., everything is cultural) as it requires the bracketing out of Nature. Similarly, scientists often also reject absolute realism (i.e., everything is natural) as it wholly brackets out Culture. Thus, as scientists generally agree that scientific knowledge is shaped by both natural and cultural factors, scientists more frequently adopt a weaker form of relativism or realism. While Nature and Culture are kept separate for both realists and relativists, there is always a relationship between Culture and Nature such that diverse cultures have different modes of accessing Nature. What is contested between the two approaches is whether knowledge about nature can be explained primarily but not exclusively through natural factors (i.e., weak realism) or through cultural factors (i.e., weak relativism). Within science education, similar discussions of realism and relativism take place (see Chapter 3 ) and are often included in curricula through exploration of the nature of science (NOS). In short, NOS addresses how the culture of science epistemologically understands and comes-to-know the nature of Nature, or ontology (e.g., Holbrook \& Rannikmae, 2007; Plakitsi, 2010; Rudolph, 2000).

However, "as soon as Nature comes into play without being attached to a culture, a third model is always secretly used" (Latour, 1993, p. 104). Latour (1993) refers to this as "particular universalism": a framework in which Nature is stable and outside of Culture and diverse cultural positionings mediate access to knowledge about Nature. The caveat, and mean through which WMS maintains primacy, is that "one society - and it is always the Western one - defines the general framework of Nature with respect to which the others are situated" (p. 105). In other words, defining how Nature operates ${ }^{11}$ is established as and establishes epistemic privilege for WMS. Again, as Barad (2007) states, "how reality is understood matters" (Barad, 2007, p. 205, emphasis in original); importantly, not only in terms of significance but also in terms of the materialization of its consequences.

Furthermore, for reasons that include but go beyond the troubling of this epistemic privilege, many critical science scholars (e.g., Barad, 2007; Kirby, 2011; Latour, 1993) have begun to examine and cast 
doubt upon the framework(s) through which questions of relativism and realism come to be argued. Under critical examination is the oft takenfor-granted assumption that many realist and relativist frameworks rely upon: Nature as a stable backdrop upon which Culture plays out. Critical science scholars, such as Haraway (1997) and Latour (1993), have long challenged the oft-accepted notion that "epistemology models ontology" (Polkinghorne, 1991, p. 304 in Cobern \& Loving, 2008, p. 442). Returning to the metaphors explored in the previous chapter, it could be stated that the notion of epistemology mirroring ontology is suspended. As Barad (2007) reminds, critical science scholarship has been labouring to displace these arguments by reading them through cultural lenses to explore what it means to inflect ontology prismatically through epistemology. By showing how the culture of science has an active role in producing scientific knowledge, this opened up rich lines of questioning regarding epistemology as always situated and partial, as well as the development of an ethics that might go alongside (e.g., Harding, 1986, 1993/2004; Latour, 1993). However, as discussed in Chapter 4, what if the nature of Nature, or ontology, were not stable and passive (i.e., the condition required for both the mirror and the prism) but rather dynamic, agentic, self-differentiated, and in an ongoing state of becoming (see Barad, 2007, 2010)? ${ }^{12}$

Within what is being referred to as the "ontological turn," Barad (2007) draws from Neils Bohr's philosophy-physics to posit that ontology is not something that exists a priori. This is to say that scientific phenomena under observation do not pre-exist their observation, rather, they are enacted with and through observation. Ontology is not separate or separable from epistemology, but rather is always entangled, superpositioned, and diffracted. Matter comes to matter in both senses of word: it is at once important and worthy of consideration; as well as something that comes into being rather than remaining inert, static, and unagentic (see also Apffel-Marglin, 2011; Barad, 2000, 2010; Kirby, 2011). ${ }^{13}$

While the realm of matter and materiality (i.e., Nature) has always been the primary focus and domain of science education, a (re)consideration of how matter comes to materialize has important consequences for science education in terms of epistemology, ontology, as well as ethics (see Bang \& Marin, 2015; Bazzul \& Kayumova, 2016; Higgins, 2016; Kayumova, McGuire, \& Cardello, 2019; Milne \& Scantlebury, 2019). Of particular importance, and a focus in this chapter, is that problem and possibility that ontology is not, and has never been, a singular affair (Barad, 2007). 
Rather, it is always already plural and becoming differential through the working and reworking of metaphysical cuts (e.g., the norms of bodily production-subjects and objects).

To situate science and science education ontologically requires one to posit an ontology, as opposed to simply situating within "ontology" (read: singular). $A n$ ontology is an ever-partial (i.e., having exclusions) but never relativistic accounting for an always shifting Nature. Barad (2007) reminds us that part of the positing of an ontology goes beyond naming which ontology is at work: the "accountability for the particular exclusions that are enacted" through our metaphysical choices includes "taking the responsibility to perpetually contest and rework the boundaries" (p. 205).

To posit an ontology thus requires, as Barad (2010) states, to consider how "science and justice" as well "matter and meaning are not separate elements that intersect now and again" (p. 242). If competing ways-ofknowing-nature are separated from their co-constitutive ontology and required to align with an ontology, specifically the ontology of WMS, then what does it mean to account for and being ethically accountable to this new entanglement? What is produced and what is producible?

\section{Why Positing an Ontology Matters: Towards ACCOUNTABILITy FOR How ReAlity Is UNDERSTOOD}

The positing of an ontology and striving towards accountability for ontological enactments is of importance for scholars working within science education, as well as those which continue to inherit its legacies. To take up the call to posit of an ontology would necessarily require moving from questions of epistemology to questions of epistemology and ontology, or even onto-epistemology (i.e., the co-constitutive entanglement of knowing and being; see Barad, 2007, 2010 $)^{14}$ to ask the question of how epistemology and ontology come to co-constitute one another.

Thus, returning to the "metaphysical choice" that Cobern and Loving (2008) present, one that asks which scientific epistemology best aligns and correlates with "ontology" (read: singular), it is fair to state that no choice is offered at all. They put forth, "there is simply no other rational way to account for human ability to increase instrumental epistemological power other than that knowledge has the characteristics of verisimilitude, vis-à-vis the real world" (p. 440). Here, because an enactment of the "real world" is already chosen by and/or for them, the "rational 
way" that Cobern and Loving's (2008) “common sense" metaphysical choice suggests is, again, WMS. Rather than present a modest intermediary position, I suggest that Cobern and Loving (2008) simply displace the terms of the multicultural science education debate by (re)presenting them anew, albeit elsewhere (see van Eijck \& Roth, 2007). ${ }^{15}$ However, what occurs to ways-of-knowing-nature that are not WMS when they are asked to "mirror" a Cartesian ontology?

While there have been invitations to position diverse ways-of-knowingnature ontologically, their alignment with the ontology of WMS produces a problematic configuration. It explicitly enunciates and upholds the often-implicit message that approaches other than WMS are lesser means of knowing nature by continuing to not only centre this ontology but also failing to acknowledge that it is but one possible ontological possibility among many. Take for example Siegel's (1997) positioning of diverse ways-of-knowing-nature other than those of WMS:

Science education must ... treat members of minority, dominated cultures with respect. And it must treat the scientific ideas of these cultures with respect. But so treating these cultures and their scientific beliefs and ideas does not require those ideas be treated as correct or as correct as the scientific ideas of the dominant, hegemonic culture. (p. 101)

Such often unacknowledged and taken-for-granted ontological positioning and posturing continues to have adverse effects on if, and how, TEK and IWLN are included within science education (see Aikenhead \& Michell, 2011; Sammel, 2009). In short, when TEK and IWLN are articulated within and/or in relation to WMS's ontology, they are not only fragmented but also potentially produced as lesser means of knowing Nature through Cartesianism.

The ontology through which WMS comes to be, Cartesianism, is the classical Western modern ontological process through which meaning and matter are individuated through separation from that which $\mathrm{co}^{-}$ constitutes them (e.g., mind/body dualism). TEK and IWLN, due to their particular relational entanglements of matter and meaning, fail to (fully) fit the constructs, categories, and concepts enacted by such an ontology; making Cartesian cuts renders many aspects of TEK and IWLN absent presences (e.g., Nature as agentic; see Cajete, 2006). While many science educators have argued that TEK and IWLN stand up to the 
terms of WMS (e.g., validity, reliability, empirical observation, repeatability), they never stand up as well as WMS on WMS' terms (Aikenhead \& Michell, 2011; Cajete, 1994, 2000). Furthermore, such a deficit-based framing (i.e., how it fails to fit WMS's epistemological and ontological enactments) obscures the importance distinctions, as well as rich contributions that TEK and IWLN have to offer from that which exceeds WMS (e.g., ethics of regeneration, spirituality; see Apffel-Marglin, 2011; Cajete, 1994, 2000).

TEK and IWLN's alignment with Cartesianism will always result in theories that are viewed as not "as correct as the scientific ideas of the dominant, hegemonic culture" (Siegel, 1997, p. 101, emphasis in original). They fail to cleanly fit the separate and mutually exclusive ontological and epistemological categories established by WMS because TEK and IWLN do not make such clean and clear cuts between epistemology and ontology and their constitutive domains. This is not to state that it is inherently wrong in an absolute sense to centre Cartesianism, ${ }^{16}$ and that there are not moments in which it is an appropriate ontology to posit (e.g., when considering WMS). ${ }^{17}$ However, to posit an ontology is to be held accountable to the patterns of difference, the lines of inclusion/exclusion that are produced through the "metaphysical choice[s]" that we make. Thus, to posit an ontology invites a differential consideration and an ongoing accounting for and ethical accountability to the ontological norms through which TEK and IWLN have been included or excluded from science education. To posit an ontology also invites a curricular investigation of how diverse knowledges are ontologically situated and produced, without needing to resort to relativism (see McKinley, 2007).

\section{Positing An(Other-Than-Cartesian) \\ Ontology: Towards Ontological Pluralism in Science Education}

One does not make the subject matter relevant by starting with an unchanged traditional curriculum and coating scientific facts with "relevant examples" to make them go down easier. In teaching for agential literacy, science is understood (not "in context") but in complex intra-action with other practices. (Barad, 2000, p. 238, emphasis in original) 
To posit an ontology within science education is to recognize that diverse ways-of-knowing-nature are not simply different ways of reaching the same ontological goal within the oft taken-for-granted or unacknowledged ontology of Cartesianism. Teaching a culturally pluralistic science classroom must go beyond the "candy coating" of the standard ontological account, "starting with an unchanged traditional curriculum and coating scientific facts with 'relevant examples' to make them go down easier" (Barad, 2000, p. 238). Rather, thinking with Barad (2000), if we are to teach in a way that encourages students to understand waysof-knowing-nature as the enacted entanglement of epistemology and ontology, then we must come to understand them as complex and coconstituted practices. In part, this entails pedagogical exploration of diverse ways-of-knowing alongside the ways-of-being that co-constitute them (e.g., Barad, 2000).

To posit an ontology is significant within the multicultural science education debate, and beyond, because it can be said that, using the language of the ontological turn, matter has always mattered to Indigenous peoples in the ways in which they come to know Nature (i.e., TEK and IWLN). In other words, Indigenous peoples have never fully enacted the nature/culture binary (i.e., the mutually exclusive bracketing of nature and culture) that is commonly accepted as a defining characteristic of Western modernity, its ontology of Cartesianism, and WMS (see Bang \& Marin, 2015; Cajete, 1994, 1999, 2000; Peat, 2002). For example, Cajete (2000) highlights the ways in which animal-human relationships conventionally map onto Nature/Culture breaks down within Indigenous ways-of-knowing-in-being:

Most Native languages do not have a specific word for 'animals.' Rather, when animals are referred to they are called by their specific names. That fact that there are no specific generic words for animals underlines the extent to which animals were considered to interpenetrate with human life. (p. 152)

Beings that are often considered within the realm of Nature (e.g., animals, plants, mountains) have always been agents within the realm of Culture (see Apffel-Marglin, 2011; Bang \& Marin, 2015; Barnhardt \& Kawagley, 2005; Cajete, 1994, 2000). Thus, to posit an ontology rather than presenting ontology as singular, universal, and pre-supposed invites a differential consideration of and an ongoing accounting for, and ethical 
accountability to, the ontological norms through which TEK and IWLN have been included or excluded from science education.

To consider ontological plurality is not a renewed commitment to relativism. Rather, there are multiple and meaningful "points of resonance" (Peat, 2002) between WMS, TEK, and IWLN. Despite these points of resonance between ways-of-knowing-in-being, this is not to suggest that there is an external reality that we can differentially access through diverse cultural frames (see Latour, 1993). Again, plurality need not be though and enacted as relativism (see McKinley, 2007). Rather than relativism, to account for and to be accountable to ontological situatedness (i.e., the coconstitutive relation between an epistemology and an ontology) might be a way of enacting what Barad (2007) asks of a re(con)figured objectivity an accounting of and for the diverse network of agents, forces, and flows which locally and globally come to produce the scientific phenomena that we seek to explore within science and science education (see also Barad, 2000).

It is nonetheless important to note that science education will be at its most fruitful when it works to engage with spaces of difference between diverse ways-of-knowing-nature to work against the ever-present risk of conflating diverse systems into sameness. This includes, but should not be limited to, the ways in which ontological sameness produces dialectic negation as discussed herein. Accounting for and being accountable to ontological difference is not only ethically significant, but epistemically generative as well: the distinctions within this plurality can help (re)shape rich and robust knowledge traditions, as well as foster the possibility of inter-cultural hybrids that bring with them the best of both worlds (e.g., Barnhardt \& Kawagley, 2005).

\section{Conclusion: Positing an Ontology as an Ethical Call}

It is not possible to extricate oneself from ethical concerns and correctly discern what science tells us about the world. Realism, then, is not about representations of an independent reality but about the real consequences, interventions, creative possibilities, and responsibilities of intra-acting within and as part of the world. (Barad, 2007, p. 37) 
While it is not "it is not possible to extricate oneself from ethical concerns and correctly discern what science tells us about the world" (Barad, 2007 , p. 37), the relationship between science (i.e., knowing nature) and justice (i.e., respecting diverse cultural knowledges) often continues to be dichotomized within the context of science education. This make it such that the debate between the pre-dominant universalist and crossculturalist positions rarely produces productive intermediary positions from which to fully take up both of these competing claims in the ways in which they are articulated. While there is a responsibility to be simultaneously accountable to both how we know and who we teach in science education, such should not foreclose the ability to respond. However, the entangled binary framings between Nature and Culture, epistemology and ontology, realism and ethics are notably framings: configurations open to being reconfigured. ${ }^{18}$ As Barad (2007) invites, realism need not strictly be an epistemological question but can also be about the "real consequences, interventions, creative possibilities, and responsibilities" (p. 37) that come with teaching and learning within science education.

Here, part of this ontological homework of response-ability is learning to account for and being accountable to the "incarnate relation that precedes the intentionality of consciousness" (Barad, 2010, p. 265) that many science educators inherit: Cartesianism and the Nature/Culture cut that it enacts. Given that the Nature/Culture binary makes science and cultural politics incommensurable (see Latour, 2004b), response-ability requires "an iterative (re)opening up to, an enabling of responsiveness" towards other-than-Cartesian possibilities. Thankfully, as Latour (1993) reminds, the Nature/Culture binary is never fully achieved or achievable. "We Have Never Been Modern", as the eponymous title of Latour's (1993) book proclaims, there is always already the possibility for knowing-in-being otherwise.

Towards this end within this chapter, I tinkered with Cobern and Loving's (2008) suggestion that the primary and almost exclusive focus on epistemologies within the multicultural science debate has detracted from considerations of how epistemology aligns with ontology. As is demonstrated herein, Cobern and Loving use this (re)signified naturalcultural interplay to make a stronger case for universalism (i.e., "Epistemic Realism Really is Common Sense" [p. 425]). However, in using and troubling their claim, there is the possibility for something else to emerge from this insight by differentially engaging with it, particularly if we also take 
seriously the notion that ontology is not a singular affair. Such differential arrangement can support us to recognize plurality can be achieved not by refuting Cobern and Loving's claim but rather by (re)situating it within a context: an epistemology of epistemic realism (i.e., the epistemology of WMS) really does align best with an ontology of Cartesianism (i.e., the ontology of WMS). To recognize that Cartesianism is but an ontology creates space in which WMS achieves "distinction not privilege" (Cobern \& Loving, 2008, p. 444), not requiring universalists' claims of onto-epistemic alignment to be refuted.

Notably, this potential for science without scientism requires science educators' response-ability towards positing an ontology, accounting for, as well as being accountable towards how it is produced and what it produces. Given science education's norms and history of inclusion/exclusion around traditional ecological knowledges and Indigenous ways-of-living-with-nature, positing an ontology invites a (re)consideration of science education's complimentary and supplementary spaces of knowing nature. Specifically, this calls for a renewed engagement with TEK and IWLN: they have their own distinct ontoepistemological alignments or entanglements, positing an ontology calls for an ethical response-ability to account for the relational ontologies which come to constitute them rather than requiring them to align with Cartesianism. To engage in such ontological pluralism need not rely on ontological or epistemological relativism as there continue to be meaningful patterns of differentiation and similarity that can be productively engaged with (see McKinley, 2007).

I conclude this chapter with further questions about the space of ethical response-ability offered by positing an ontology: if how we think (e.g., Nature/Culture binary) is the very thing preventing forward momentum within the multicultural science education debate, how do we think about how we think without using the very thing with which we think? How might science educators move towards ethical responseability when responsibility is not something that we simply have that pre-exists our engagements but rather is also something by which we are had, that is produced in its complex flow through and by us? What further homework might allow us to be accountable to how we are always already (re)produced by science education as educators? Similarly, how can we foster response-ability to what we produce within the everchanging field of possible possibilities of science education (as part of the world's ongoing becoming)? Lastly, what types of theory-practices 
might facilitate the $\mathrm{im} /$ possible but necessary accounting for what our onto-epistemological enactments produce within science education? ${ }^{19}$ Response-ability, as Barad (2010) reminds, is not achieved "through the realization of some existing possibility, but through the iterative reworking of im/possibility" (p. 265). While there is no singular solution to such questions, positing an ontology paves pathways to engage with the im/possibility of being wholly accountable and ethically responsive. To reiterate, situating science education ontologically by positing an ontology is not about who is right or who is wrong, nor is it about a renewed commitment to relativism. Rather, it is about coming-torecognize a plurality of possibilities, and in turn, it means being accountable to how scientific knowledge is produced, produce-able, and what it produces in turn within and beyond the science education classroom. Because "how reality is understood matters" (Barad, 2007, p. 205), the (re)working of lines of inclusion/exclusion that such understandings and enactments produce are always already becoming something else, and this (re)working towards positing an ontology is an ethical call which we must all heed, albeit differently.

\section{Notes}

1. An earlier version of this chapter appears in Milne's and Scantlebury (2019) Material Practice and Materiality: Too Long Ignored in Science Education (pp. 67-79), and is reprinted with permission.

2. Recall from Chapter 3 that the interplay of absence and presence signals the play of (re)signification. Absent presences are other(ed) signified meanings that might nonetheless retain the structure of the signifier that act as the constitutive otherness of that which is usually signified (see Spivak, 1993/2009). However, absent presences are not an unproblematic panacea: they are at once both unstated and un-assumed meanings (e.g., how claims of science education without scientism have not wholly done away with it) as well as those whose potentiality might allow for justice tocome (e.g., such as pedagogical plurality, allowing for Indigenous science to-come).

3. As Dr. Apffel-Marglin offers in the interview in the next chapter, it is always important to remain open to knowledge outside of one's particular disciplinary pathway. Drawing from that which is uncommon (i.e., other disciplines) can become productive tools to tinker with to (re)open the common (i.e., the occupied disciplinary space).

4. Further, if the goal is to (re)open science education, part of tinkering might entail either: (a) utilizing tools and techniques intended for science 
education, but refusing to use them in intended ways; or, (b) putting to work tools and techniques not intended for use within science education (see Higgins, Wallace, \& Bazzul, 2018 for exemplars of this in STEM education).

5. See Chapter 2 for a more fulsome account of this narrative vignette, albeit one differentially situated in relation to the content of that chapter (i.e., towards introducing and thinking with response-ability).

6. Once more, this mantra is to remind that with respect to the question of Indigeneity within science education, there is no "beginning": we are always already in relation. Accordingly, the plurality of "beginnings" from which we can account for and be accountable to are a resource rather than a liability.

Further, the invitation within this chapter signals the ways in which metaphysics of Western modernity makes itself common, to the extent that it is often, and (too) simply, referred to as common sense. For example, the (neo-)colonial desire for and production of origins (see TallBear, 2013). Within the metaphysics of cloture, the process is rendered one and the same as its product (see Derrida, 1976). This is to say that origins are treated as if they were and could only singular in nature: this is their ontological status (where ontology here is to be read exclusively as the Being of beings). To say the least, this makes it difficult to account for and be accountable to the agencies that are active in the production of an origin. For example, TallBear's (2013) research complicates the common sensical notion that who Indigenous people are (Being) originates in their DNA. She does this not only by offering an Indigenous conception of Being that is (ontologically) relational, but calling into question the ways in which this "common" (read: made common through colonialism) sense shapes problematic extractivist genetic practices (i.e., taking genetic samples from Indigenous peoples to save them, rooted in an image of "vanishing Indian" that is disassociated from Western modernity's complicity in the production of this image, or the genocides which may have come to inform it).

Which is to say, yet again, that we, who identify and are identifiable as science educators, are already within relation with Indigeneity, even if most of us are not Indigenous; that deferring and differing an origin is not strictly a theoretical move for theory's sake, but one that has effects that come to matter, in both senses of the word.

7. Reminder from the previous chapter that equally valid does not signify that TEK and IWLN achieve equivalence or sameness with WMS, and particularly not necessarily on the same terms. Rather that they offer something that is of differently significant and productive (see Aikenhead \& Ogawa, 2007). 
8. Latour (2004b) reminds that common sense and good sense are often opposed rather than one and the same. However, he goes on to suggest that if the "good-ness" of sense is pre-supposed, the possibility of meaning being made through common understanding (i.e., dialogue) rather than made common through dialectic is (fore)closed.

Also, the question of how this particular "common sense" is produced and what it produces in turn is taken up in far greater detail in the latter, and more substantive, half of this section (i.e., Chapter 6).

9. This is to be differentiated from the taken-for-granted relationship that Barad (2000) alerts us to: one in which scientific literacy is perceived as always already ethical. As she states, it is often assumed that:

[There is an] equivalence relation between the possession of scientific knowledge and being socially responsible [that] is often implicit in discussions about scientific literacy: this is the notion that familiarity with the facts and the methods of science is all that is required for socially responsible decision-making concerning science- and technology-related issues. (Barad, 2000, p. 227)

This ontological pre-determination of ethicality masks the ways in which the (im)possibility of ethics is never fully achieved or achievable as well as how science and science education must always remain ethically on the move and vigilant to respond to an ever-evolving set of ethical problems and possibilities (see also Roth, 2003).

10. With experience being a central concept here, as well as the larger field of education, it is important to recognize that we may not all be referring to the same understanding and enactment of the concept: experience comes to take many forms (above and beyond its doubly settled meaning).

For example, being had by experience might signal at once the ways in which experience "gets the best of us," as well as the ways in which we might not "have" experiences (as possession). Rather, due to not "having" a static body of meaning or matter (i.e., the meaning and matter which makes us is never fully ours; distributed agency; see Barad, 2007; Butler, 2005; Chapter 2 on moving beyond the "I" as subject of ethics and inquiry). What remains from experiences (e.g., learnings), when we are had by them, are the marks left on our body (of meaning and matter) from the intensities and flows within the multiple assemblages we find ourselves in and the affective movement of meaning, matter, spirit with/in/around the re(con)figured body we are part of (see Apffel-Marglin, 2011).

11. Notably, particular universalism dictates how Nature operates without Nature's consent (see Barad, 2007, 2012). As Latour (1993) and Cajete $(1994,2000)$ state, this double(d) othering of Nature and of other-thanWestern cultures are not separate nor separable enactments but rather 
differential enactments of the same, intertwined through a practice of cultural "transcendence" in which WMS sees itself as neither having a culture nor being part of Nature.

12. This is of particular significance as Nature as agentic, differentiated, and fluid is important to how an Indigenous "sense of place" is understood and enacted (see Bang \& Marin, 2015; Cajete, 2006).

13. Recall, from the preface, that the "ontological turn" is not wholly a panacea when responding to the question of Indigeneity; it is also a poison. As Barad (2007) invites, positing an ontology is also about "insisting on accountability for the particular exclusions that are enacted and in taking the responsibility to perpetually contest and rework the boundaries" (Barad, 2007, p. 205); here, the ontological turn is not excluded within the critical gaze. Specifically, this turn in educational research (and the broader humanities) often fails to acknowledge the ways in which many Indigenous peoples have been thinking about and practising with the other-than-human world since time immemorial, and also have rich conceptions of ontological fluidity and relationality. Whether intended or not, a citational politics at the ontological turn that does not acknowledge Indigeneity reproduces, albeit differently, (neo-)colonial logics by suturing over and sublating Indigenous ways-of-knowing-in-being.

At the same time, a significant part of the homework of responseability is work to within and against the language that we inherit, here it is that of science (e.g., here, drawing from critical science studies), as a means of simultaneously coming-to-know the location from which knowledge is constructed and (re)opening the ability to respond. Further, as Kuokkanen (2007) invites, including the work of (relatively) wellknown scholars into the conversation can "summon" connections and connectivities that might otherwise dismiss questions and considerations of Indigeneity. Lastly, as Spivak (1994) reminds, to denegate a particular theory or approach based on its cultural location alone can create habits in which we too simply dismiss what a particular theory might offer (particularly in terms of undoing its own situationality) while simultaneously uncritically embrace theories from the "correct" location. This has the likely unintended, but not unproblematic effect, of leaving many off-thehook if the implicit message that they are inherently incapable of escaping their own positionality: this is not insignificant considering that the field of science education is mostly based in a Western training in science and that there are many who are white (and/or are complicit in whiteness).

14. Onto-epistemology can neither be adequately referred to as both ontology and epistemology, nor the two as one, but rather a state of superposition and co-constitution (see Barad, 2007, 2010). 
15. While this is (what I imagine to be) the intended purpose of their contribution to the science education literature, to tinker is to purpose-fully (i.e., intentionally and with purpose) (mis)use tools and concepts.

16. It is important to note however that Cartesianism and Eurocentrism co-constitute one another and that particular attention needs to be paid to how these produce science education and educator, as well what such a science curriculum and pedagogy might come to produce (see Higgins, 2014; see also Apffel-Marglin, 2011; Battiste, 2005; Cajete, 1994).

17. Part of the reason for this, if we take Barad's (2007) notion of ontoepistemology seriously, is that the epistemology and ontology of WMS are always already simultaneously enacted (see also Latour, 1993, 2004b). Furthermore, it has been argued that the two were also historically co-developed (see Apffel-Marglin, 2011).

18. Recall from the previous chapter that distance and separation are never neutral: they are part of the (neo-)colonial grammar and practice which comes to constitute the centre (e.g., WMS) and the margins (e.g., IWLN). In turn, these configurations are not only open to being re(con)figured, but that part of the work of hospitably receiving Indigenous ways-of-knowing-in-being in science education is to address this part of our homework: coming-to-know and address the ontological "home" which complicates and forecloses the possibility of Indigenous science to-come in science education.

19. For example, Lather (2007) suggests a double(d) reversal of the ethnographic gaze to consider not only the ways in which thought is prismatically inflected, but also the entangled apparatus through which thought it is produced and producible. Such a double(d) reversal entails both the literal reversal of studying those who do the studying (i.e., in order to reverse the direction of the ethnographic gaze), as well as the study of the way in which those who do the studying study (i.e., in order to reverse the way in which the ethnographic gaze is produced). In the second and more substantive part this section (i.e., Chapter 6), I engage with and through an interview with Dr. Apffel-Marglin who engaged in the difficult task of a double(d) reversal around how Cartesianism is produced and what it produces.

\section{REFERENCES}

Aikenhead, G. S., \& Michell, H. (2011). Bridging cultures: Indigenous and scientific ways of knowing nature. Toronto, ON: Pearson Canada Inc.

Aikenhead, G. S., \& Ogawa, M. (2007). Indigenous knowledge and science revisited. Cultural Studies of Science Education, 2(3), 539-620. 
Alsop, S., \& Fawcett, L. (2010). After this nothing happened. Cultural Studies of Science Education, 5(4), 1027-1045.

Apffel-Marglin, F. (2011). Subversive spiritualities: How rituals enact the world. New York, NY: Oxford University Press.

Bang, M., \& Marin, A. (2015). Nature-culture constructs in science learning: Human/non-human agency and intentionality. Journal of Research in Science Teaching, 52(4), 530-544.

Barad, K. (2000). Reconceiving scientific literacy as agential literacy. In R. Reed \& S. Traweek (Eds.), Doing science + culture (pp. 221-258). New York, NY: Routledge.

Barad, K. (2007). Meeting the universe halfway: Quantum physics and the entanglement of matter and meaning. Durham, NC: Duke University Press.

Barad, K. (2010). Quantum entanglements and hauntological relations of inheritance: Dis/continuities, spacetime enfoldings, and justice-to-come. Derrida Today, 3(2), 240-268.

Barad, K. (2012). Nature's queer performativity. Kvinder, Køn \& Forskning, $1(2), 25-53$.

Barnhardt, R., \& Kawagley, A. (2008). Indigenous knowledge systems and education. Yearbook of the National Society for the Study of Education, 107(1), 223-241.

Barnhardt, R., \& Kawagley, O. (2005). Indigenous knowledge systems and Alaska Native ways of knowing. Anthropology \& Education Quarterly, 36(1), 8-23.

Battiste, M. (2005). You can't be the global doctor if you're the colonial disease. In P. Tripp \& L. J. Muzzin (Eds.), Teaching as activism (pp. 121-133). Montreal, QC: Queen's University Press.

Bazzul, J., \& Kayumova, S. (2016). Toward a social ontology for science education: Introducing Deleuze and Guattari's assemblages. Educational Philosophy and Theory, 48(3), 284-299.

Belczewski, A. (2009). Decolonizing science education and the science teacher: A white teacher's perspective. Canadian Journal of Science, Mathematics and Technology Education, 9(3), 191-202.

Bohm, D. (1996). On dialogue. New York, NY: Routledge.

Butler, J. (2005). On giving an account of oneself. New York, NY: Fordham University Press.

Cajete, G. (1994). Look to the mountain: An ecology of indigenous education. Durango, CO: Kikavi Press.

Cajete, G. (1999). Igniting the sparkle: An Indigenous science education model. Durango, CO: Kivaki Press.

Cajete, G. (2000). Native science: Natural laws of interdependence. Santa Fe, NM: Clear Light Books. 
Cajete, G. (2006). Western science and the loss of natural creativity. In F. Arrows (Ed.), Unlearning the language of conquest: Scholars expose anti-Indianism in America (pp. 247-259). Austin, TX: University of Texas Press.

Carter, L. (2004). Thinking differently about cultural diversity: Using postcolonial theory to (re)read science education. Science Education, 88(6), 819-836.

Carter, L. (2010). The armchair at the borders: The 'messy' ideas of borders, border zones and epistemological diversity in multicultural science education. Science Education, 94, 1-20.

Cobern, W. W., \& Loving, C. C. (2001). Defining "science" in a multicultural world: Implications for science education. Science Education, 85, 50-67.

Cobern, W. W., \& Loving, C. C. (2008). An essay for educators: Epistemological realism really is "common sense". Science \& Education, 17, 425-447.

Derrida, J. (1976). Of grammatology (G. C. Spivak, Trans.). Baltimore, MD: John Hopkins University Press.

El-Hani, C. N., \& de Ferreira Bandeira, F. P. S. (2008). Valuing Indigenous knowledge: To call it "science" will not help. Cultural Studies of Science Education, 3(3), 751-779.

El-Hani, C. N., \& Mortimer, E. F. (2007). Multicultural education, pragmatism, and the goals of science teaching. Cultural Studies of Science Education, 2(3), $657-702$.

Haraway, D. (1997). Modest_Witness@Second_Millennium.FemaleMan_Meets_ OncoMouse. New York, NY: Routledge.

Harding, S. (1986). The science question in feminism. Ithaca, NY: Cornell University Press.

Harding, S. (1993/2004). Rethinking standpoint epistemology: What is "strong objectivity"? In S. Harding (Ed.), The feminist standpoint theory reader: Intellectual \& political controversies, (pp. 127-140). New York, NY: Routledge.

Higgins, M. (2011). Finding points of resonance: Nunavut students' perceptions of science. in education, $17(3), 17-37$.

Higgins, M. (2014). De/colonizing pedagogy and pedagogue: Science education through participatory and reflexive videography. Canadian Journal of Science, Mathematics and Technology Education, 14(2), 154-171.

Higgins, M. (2016). Decolonizing school science: Pedagogically enacting agential literacy and ecologies of relationships. In C. Taylor \& C. Hughes (Eds.), Posthuman research practices (pp. 186-205). Basingstoke, UK: Palgrave Macmillan.

Higgins, M., Wallace, M. F., \& Bazzul, J. (2018). Disrupting and displacing methodologies in STEM education: From engineering to tinkering with theory for eco-social justice. Canadian Journal of Science, Mathematics and Technology Education, 18(3), 187-192. 
Holbrook, J., \& Rannikmae (2007). The nature of science education for enhancing scientific literacy. International Journal of Science Education, 29(11), 1347-1362.

Kayumova, S., McGuire, C. J., \& Cardello, S. (2019). From empowerment to response-ability: Rethinking socio-spatial, environmental justice, and natureculture binaries in the context of STEM education. Cultural Studies of Science Education, 14(1), 205-229.

Kirby, V. (2011). Quantum anthropologies: Life at large. Durham, NC: Duke University Press.

Kuokkanen, R. J. (2007). Reshaping the university: Responsibility, Indigenous epistemes, and the logic of the gift. Vancouver, BC: UBC Press.

Lather, P. (2007). Getting lost: Feminist efforts toward a double(d) science. New York, NY: State University of New York.

Latour, B. (1993). We have never been modern. Cambridge, MA: Harvard University Press.

Latour, B. (2004a). Why has critique run out of steam? From matters of fact to matters of concern. Critical Inquiry, 30(2), 225-248.

Latour, B. (2004b). Politics of nature: How to bring the sciences into democracy. Cambridge, MA: Harvard University Press.

Matthews, M. R. (1994). Science teaching: The role of history and philosophy of science. New York, NY: Routledge.

McKinley, E. (2001). Cultural diversity: Masking power with innocence. Science Education, 85(1), 74-76.

McKinley, E. (2007). Postcolonialism, Indigenous students, and science education. In S. K. Abell \& N. G. Lederman (Eds.), Handbook of research on science education (pp. 199-226). Mahwah, NJ: Lawrence Erlbaum.

Milne, C., \& Scantlebury, K. (2019). Material practice and materiality: Too long ignored in science education (Vol. 18). Cham, Switzerland: Springer.

Peat, D. (2002). Blackfoot physics: A new journey into the Native American universe. Newbury Port, MA: Weiser Books.

Plakitsi, K. (2010). Collective curriculum design as a tool for rethinking scientific literacy. Cultural Studies of Science Education, 5(3), 577-590.

Pillow, W. (2003). Confession, catharsis, or cure? International Journal of Qualitative Studies in Education, 16(2), 175-196.

Roth, W. M. (2003). Scientific literacy as an emergent feature of collective human praxis. Journal of Curriculum Studies, 35(1), 9-23.

Rudolph, J. L. (2000). Reconsidering the "nature of science" as curriculum component. Journal of Curriculum Studies, 32(3), 403-419.

Sammel, A. (2009). Turning the focus from 'other' to science education: Exploring the invisibility of whiteness. Cultural Studies of Science Education, 4, 649-656. 
Siegel, H. (1997). Science education: Multicultural and universal. Interchange, $28,97-108$.

Siegel, H. (2001). Multiculturalism, universalism, and science education: In search of common ground. Science Education, 86, 803-820.

Snively, G., \& Corsiglia, J. (2001). Discovering Indigenous science: implications for science education. Science Education, 85, 6-34.

Spivak, G. C. (1993/2009). Outside in the teaching machine. New York, NY: Routledge.

Spivak, G. C. (1994). Responsibility. boundary 2, 21(3), 19-64.

Stanley, W. B., \& Brickhouse, N. W. (2001). Teaching sciences: The multicultural question revisited. Science Education, 85, 35-49.

TallBear, K. (2013). Native American DNA: Tribal belonging and the false promise of genetic science. Minneapolis, MN: University of Minnesota Press.

van Eijck, M., \& Roth, W. M. (2007). Keeping the local local: Recalibrating the status of science and traditional ecological knowledge (TEK) in education. Science Education, 91(6), 926-947. https://doi.org/10.1002/sce.20227.

Wildcat, D. R. (2005). Indigenizing the future: Why we must think spatially in the twenty-first century. American Studies, 46, 417-440.

Open Access This chapter is licensed under the terms of the Creative Commons Attribution 4.0 International License (http://creativecommons.org/licenses/ by $/ 4.0 /)$, which permits use, sharing, adaptation, distribution and reproduction in any medium or format, as long as you give appropriate credit to the original author(s) and the source, provide a link to the Creative Commons license and indicate if changes were made.

The images or other third party material in this chapter are included in the chapter's Creative Commons license, unless indicated otherwise in a credit line to the material. If material is not included in the chapter's Creative Commons license and your intended use is not permitted by statutory regulation or exceeds the permitted use, you will need to obtain permission directly from the copyright holder.

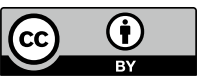

